\title{
Structural Characterisation of Asphaltenes during Residue Hydrotreatment with Light Cycle Oil as an Additive
}

\author{
Yong-Jun Liu and Zhi-Feng Li \\ College of Chemical Engineering, Huaqiao University, Jimei 668, Xiamen, Fujian 361021, China \\ Correspondence should be addressed to Yong-Jun Liu; yongjunliu@hqu.edu.cn
}

Received 23 January 2015; Accepted 5 March 2015

Academic Editor: Tomokazu Yoshimura

Copyright (C) 2015 Y.-J. Liu and Z.-F. Li. This is an open access article distributed under the Creative Commons Attribution License, which permits unrestricted use, distribution, and reproduction in any medium, provided the original work is properly cited.

\begin{abstract}
Several atmospheric residues (AR) of Kuwaiti crude, in the absence, or in the presence, of light cycle oil (LCO) as an aromatic additive, were hydrotreated in an experimental plant. Asphaltenes (precipitated from Kuwaiti AR, a hydrotreated AR, and a hydrotreated blend of AR and LCO) were characterised by chemical structure and changes during residue hydrotreatment. The average structural parameters of these asphaltenes, obtained from a combined method of element analysis, average molecular weight, X-ray diffraction, and NMR, demonstrate that, after hydrotreatment, the aromatic cores of the asphaltenes become more compact and smaller whereas the peripheral alkyl branches are decreased in number and shortened. The influence of LCO on residue hydrotreating is also studied in terms of structural changes in the asphaltenes. The findings imply that LCO added to AR during hydrotreating improves the degree of aromatic substitution, the total hydrogen/carbon atomic ratio per average molecule, the distance between aromatic sheets and aliphatic chains, and so forth, by modifying the colloidal nature and microstructure of asphaltene: this is beneficial for the further hydroprocessing of AR. Three hypothetical average molecules are proposed to represent the changes undergone by such asphaltenes during hydrotreatment as well as the effects of additive LCO.
\end{abstract}

\section{Introduction}

Asphaltenes are the most complex molecules in petroleum and consist of highly condensed polyaromatic units bearing long aliphatic and alicyclic substituents with heteroatoms $(\mathrm{O}$, $\mathrm{N}$, and S) as part of the aromatic system and trace metals as porphyrins. They are commonly presumed to represent the most refractory and difficult portion of the feedstock to process. In the particular case of the hydrotreatment (HDT) of heavy oil, the following problems can be caused by asphaltenes $[1,2]:(1)$ they reduce the overall rate at which the hydrodesulfurization reaction occurs, (2) they precipitate on the catalyst surface and block the pore throat, and (3) they act as coke precursors which in turn lead to deactivation of the HDT catalysts. To understand the mechanisms underpinning these problems, it is then mandatory to examine the changes in asphaltene structure and composition. A deeper knowledge of their properties can be a valuable aid in achieving a better understanding of their behavior during the hydrotreatment of heavy oils.

Tremendous strides have been made in asphaltene science; the most influential work is the Yen model or modified
Yen model proposed by Teh Fu Yen, Mullins, and their coworkers [3, 4]. This model, mainly obtained from Xray diffraction and mass spectrometer analysis, is used to account for asphaltene characteristics and establish structurefunction relationships and causality therein. From then on, many advanced analytical techniques have been applied to asphaltenes, providing correct asphaltene parameters and molecular structures [5-9]. Thereinto, ${ }^{1} \mathrm{H}$ and ${ }^{13} \mathrm{C}$ NMR provide information regarding the relative amounts of each form of structural composition in an asphaltene. In conjunction with elemental analysis and average molecular weight data, it is possible to obtain quantitative information about the different types of protons and carbons present [10-12]. Based on the structural parameters, model structures have been proposed for asphaltenes and higher residues $[13,14]$. It may help in the understanding of changes that occur at the molecular level when asphaltenes are subjected to processes such as thermal cracking, catalytic hydrogenation, and pyrolysis among others.

XRD is a nondestructive method that has been established for the determination of structural parameters in 
carbonaceous materials. The fractions of amorphous carbon, aromaticity, interlayer spacing of the crystalline structure $\left(d_{002}\right)$, and crystallite sizes have been established as structural parameters for evaluating the carbon stacking structure in carbon materials [15-17]. In consideration of the respective features and advantages of XRD and NMR, some researchers $[4,17,18]$ have improved upon the quality of structural information pertaining to asphaltenes by combining XRD and NMR techniques. For example, Siddiqui [18] studied the changes in asphaltene structure during pyrolysis and hydrothermal reactions on several catalysts by NMR and XRD (combined with other techniques) and then proposed a hypothetical residue/asphaltene structure for expounding the different reaction paths during catalytic pyrolysis.

Although many significant conclusions, usually focusing on the nature of the structure of asphaltenes, have been drawn, the structural modification of asphaltene molecules by additives, such as light cycle oil and heavy cycle oil, have not been studied thoroughly, and the role of additives still needs to be further investigated. It is well-known that asphaltenes exhibit a characteristically colloidal nature. In a typical colloidal petroleum-based system, the dispersed phase comprises a nucleus (a super-molecule structure including asphaltenes and resins as well as intermediate substances) and a surrounding solvate shell (hydrocarbons of a lower aromaticity and lower molar mass). The asphaltene colloidal structure can be modified by introducing special additives $[19,20]$. Therefore, some reseachers consider aromatic distillates from petroleum as additives to improve heavy oil hydroprocessing. Recently, we proposed a modification mechanism for the asphaltene colloid by introducing aromatic additives $[21,22]$. When aromatic additives, such as light cycle oil and heavy cycle oil, are introduced, a dissolution equilibrium between the nucleus and the oil should be considered. It is hypothesised that the chemical potentials of aromatic compounds therein should be equal to maintain equilibrium. The addition of high-aromaticity additives increases the solubility of aromatic compounds in oil; therefore, resins in asphaltene are apt to transfer to the oil. Asphaltene becomes less compact and is easily dissociated into smaller structures under certain conditions. In the presence of high-aromaticity additives, some polycyclic aromatic hydrocarbon sheets in the core of these asphaltenes may even be dissolved under high temperatures.

In the present work, we attempted to provide novel insights into the structural evolution of asphaltenes during residue hydrotreatment from microstructural and average parameter perspectives. In particular, we focused on the modification of aromatic additives and that effect on the nature of asphaltene and the improvement in RHT performance. On the basis of the structural parameters obtained from combined XRD, NMR, element analysis, and TOFMS, three hypothetical average molecules were proposed to describe changes in asphaltenes during RHT and the effects of additive LCO thereon.

\section{Experimental}

2.1. Residue Hydrotreating Experiments. A commercial $\mathrm{NiMo} / \mathrm{Al}_{2} \mathrm{O}_{3}$ (Mo 5.61 wt\%, Ni $2.16 \mathrm{wt} \%$ ) catalyst was used in residue hydrotreatment experiments. In a sealed box filled with $\mathrm{N}_{2}$, the feedstock, namely, an AR obtained from Kuwaiti crude or a blend of AR and LCO (5 wt\%) was charged with a presulphided catalyst sample into an autoclave, the inner volume of which was $150 \mathrm{~mL}$. The autoclave was pressurised to $8 \mathrm{MPa}$ (a hydrogen atmosphere was used therein) at ambient temperature and was then heated to $350^{\circ} \mathrm{C}$. After a reaction time of $5 \mathrm{~h}$, we cooled the reactor using cold water and then took samples for analysis.

2.2. Precipitation of Asphaltenes. Asphaltenes were precipitated from AR, a hydrotreated AR, and a hydrotreated blend of AR and LCO according to the method described in ASTM D3279, which uses $n$-heptane for solvent extraction. The solvent-to-feed ratio was $5: 1(\mathrm{v} / \mathrm{w})$. Precipitation conditions were a pressure of $25 \mathrm{~kg} / \mathrm{cm}^{2}$, a temperature of $60^{\circ} \mathrm{C}$, and a stirring rate of $750 \mathrm{rpm}$. The resulting samples were marked AR-F-ASP, AR-P-ASP, and ARLCO-P-ASP, respectively.

2.3. Element Analysis. The concentrations of $\mathrm{C}, \mathrm{H}, \mathrm{N}$, and $\mathrm{O}$ in asphaltenes before and after hydroprocessing were measured by an element analysis instrument CHN-O-Rapid (Heraeus). An X-ray fluorescence analyser was used to determine the fluorescence strength of $S$ in the samples, and then their mass fractions were calculated by using a working curve.

2.4. Molecular Mass Analysis. The molecular measurements were performed with a matrix-assisted laser desorption ionisation mass spectrometer equipped with a time-of-flight analyser (MALDI TOF-MS, JEOL JMS-ELITE II). In all cases a $20 \mathrm{kV}$ accelerating voltage was used with pulsed ion extraction. A nitrogen laser $(337 \mathrm{~nm}, 3 \mathrm{~ns}$ pulse width, 106$107 \mathrm{~W} / \mathrm{cm}^{2}$ ) operating at $4 \mathrm{~Hz}$ was applied to produce laser desorption. Asphaltene samples were introduced to the mass spectrometer by dissolving them in toluene, spotting $10 \mu \mathrm{L}$ of that solution onto a stainless steel platter, and allowing it to air-dry and then inserting the platter into a vacuum chamber. Each spectrum was the average of 30 shots.

2.5. X-Ray Diffractometry. X-ray diffractograms of the powdered samples were obtained with a high-power $(12 \mathrm{~kW})$ $\mathrm{X}$-ray diffractometer containing a rotating copper anode, a graphite monochromator, and a scintillation counter. The diffraction patterns $\left(5^{\circ} \leq 2 \theta \leq 110^{\circ}\right)$ were recorded at room temperature using $\mathrm{Cu} \mathrm{K}_{\alpha}$ radiation $(\lambda=1.54055 \AA)$ at a scanning rate of $1 \mathrm{deg} \cdot \mathrm{min}^{-1}$ and a step size of $0.02(2 \theta)$. Using a software program (Origin 8.0), the recorded patterns were smoothed, corrected for $\mathrm{K}_{\alpha} 2$, and deconvoluted; then peak position, peak intensity, peak area, interplanar distance, and full width at half maximum (FWHM) were calculated.

2.6. Nuclear Magnetic Resonance Spectroscopy. ${ }^{1} \mathrm{H}$ and ${ }^{13} \mathrm{C}$ NMR spectra were recorded on a JNM-ECA 600 (JEOL) NMR spectrometer operating at 400 and $600 \mathrm{MHz}$, respectively. The sample solutions were prepared in chloroform-d; tetramethylsilane was used as an internal standard. Quantitative ${ }^{13} \mathrm{C}$ NMR spectra were recorded by adding a relaxation agent, chromium (III) 2, and 4-pentanedionate $(10 \mathrm{mg} / \mathrm{L})$ 
TABLE 1: Element analysis of asphaltene fractions in feed and products.

\begin{tabular}{lccc}
\hline Element, \% & AR-F-ASP & AR-P-ASP & ARLCO-P-ASP \\
\hline $\mathrm{H}^{\mathrm{a}}$ & 9.43 & 8.11 & 8.79 \\
$\mathrm{C}^{\mathrm{a}}$ & 83.01 & 84.56 & 84.13 \\
$\mathrm{~N}^{\mathrm{a}}$ & 0.81 & 0.90 & 1.07 \\
$\mathrm{O}^{\mathrm{b}}$ & 3.38 & 4.01 & 4.68 \\
$\mathrm{~S}^{\mathrm{c}}$ & 3.373 & 1.419 & 1.331 \\
$\mathrm{H} / \mathrm{C}^{\mathrm{d}}$ & 1.36 & 1.15 & 1.25 \\
\hline
\end{tabular}

${ }^{\mathrm{a}}$ Derived from CHN element analysis; ${ }^{\mathrm{b}}$ subtracted H, C, N, and S from $100 \%$; ${ }^{c}$ derived from XRF analysis; ${ }^{\mathrm{d}}$ atomic ratio.

Molecular formulae: AR-F-ASP $\mathrm{C}_{120} \mathrm{H}_{163} \mathrm{~N}_{1.0} \mathrm{~S}_{1.8} \mathrm{O}_{3.7}$, AR-P-ASP $\mathrm{C}_{110} \mathrm{H}_{126} \mathrm{~N}_{1.0} \mathrm{~S}_{0.7} \mathrm{O}_{3.9}$, and ARLCO-P-ASP C $\mathrm{C}_{92} \mathrm{H}_{115} \mathrm{~N}_{1.0} \mathrm{~S}_{0.5} \mathrm{O}_{3.8}$.

in the inverse gated condition. The amount of relaxation agent was sufficient to relax all the quaternary carbons in the aromatic region, since there was no change in intensity upon further increasing the amount of relaxation agent used. The relaxation delay $\left(D_{1}\right)$ was $2.3 \mathrm{~s}$ and 20,000 to 30,000 scans were recorded to improve the signal-to-noise ratio sufficiently.

\section{Results and Discussion}

3.1. Element Analysis and Molecular Mass Analysis of Asphaltenes. Element analytical data of asphaltene fractions in feed and products are shown in Table 1. As an integrated result from Table 1, the average molecular formulae of AR-F-ASP, AR-P-ASP, and ARLCO-PASP were $\mathrm{C}_{120} \mathrm{H}_{163} \mathrm{~N}_{1.0} \mathrm{~S}_{1.8} \mathrm{O}_{3.7}, \mathrm{C}_{110} \mathrm{H}_{126} \mathrm{~N}_{1.0} \mathrm{~S}_{0.7} \mathrm{O}_{3.9}$, and $\mathrm{C}_{92} \mathrm{H}_{115} \mathrm{~N}_{1.0} \mathrm{~S}_{0.5} \mathrm{O}_{3.8}$, respectively.

The H/C atomic ratios of hydrotreated asphaltenes, ARP-ASP and ARLCO-P-ASP, were lower than that of nonhydrotreated AR-F-ASP. As mentioned above, asphaltene consists of a high-aromaticity nucleus and a surrounding solvate shell. During hydrotreatment, the surrounding branched alkyl substituents were easily ruptured from the aromatic nucleus. The higher aromatic constituents (lower $\mathrm{H} / \mathrm{C}$ ratio) remained and were even precipitated from oil or coking substances because of disruption of the dissolution equilibrium. The contents of heteroatomic $\mathrm{O}$ and $\mathrm{N}$ increased after hydrotreatment, accompanied by a decline in S-content. This can be attributed to different styles of heteroatoms in asphaltene. $\mathrm{O}$ and $\mathrm{N}$ are mainly entangled in the aromatic nucleus or chelated to other central atoms by their high polarity, resulting in the difficulty in their removal, whereas $S$ mainly occurs as reactive sulphur, for example, thioether and bridge sulphur. By comparing the hydrotreatment products AR-P-ASP and ARLCO-P-ASP, the asphaltene precipitated from the hydroprocessed blend of AR and LCO exhibited a higher $\mathrm{H} / \mathrm{C}$ atomic ratio and better removal efficiencies of $\mathrm{S}$, which implied that the added LCO was helpful when modifying the structure of hydrotreated asphaltenes and improving the performance of residue hydrotreatment.

Laser desorption TOF-MS resulted in little fragmentation of the asphaltene molecules and, thus, was a good technique for determining the molecular weight of the individual

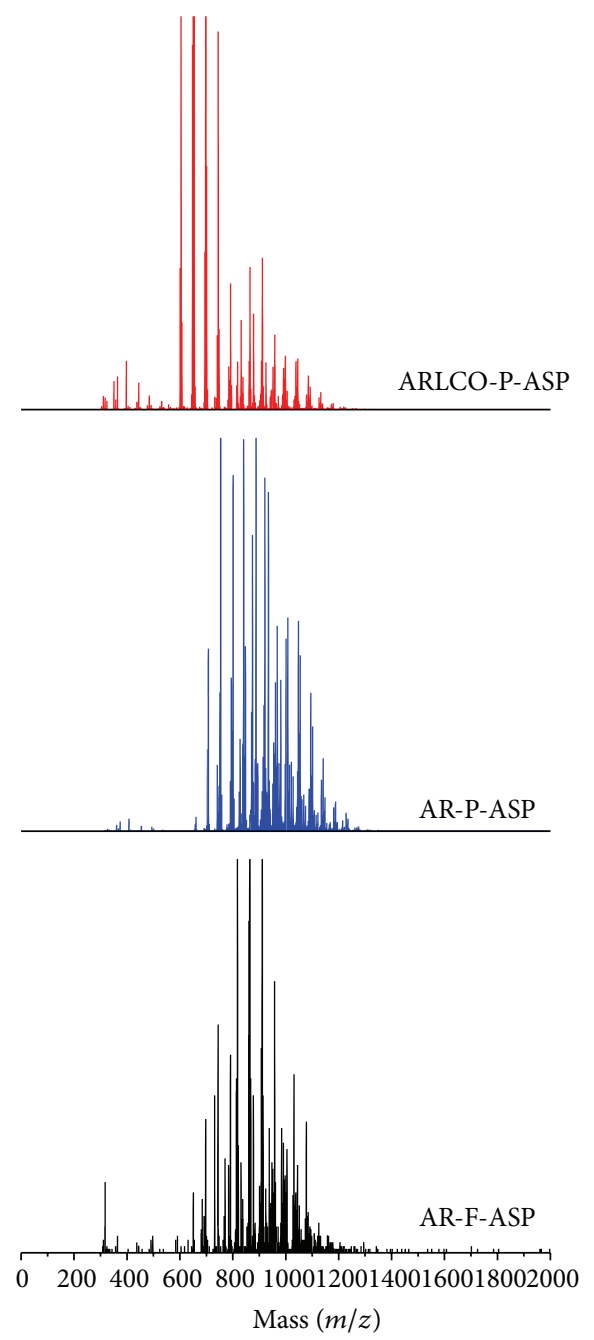

FIGURE 1: TOF-MS spectra of asphaltenes before and after hydrotreating.

molecules in complex mixtures. The mass distributions of the hydrotreated asphaltenes are shown in Figure 1 along with that of the initial feed asphaltene for comparison. Each asphaltene displayed a similar molecular weight distribution from 600 to 1,300 Daltons. The mass distribution of ARP-ASP showed slightly more heavy molecules than that of AR-F-ASP, while the largest presence of ARLCO-P-ASP shifted to a lower mass. This result indicated that, during hydrotreatment, some inflexible components of asphaltene were further condensed when some surrounding paraffin and naphthenic rings were hydrocracked or pyrolyzed. As mentioned, LCO enhanced the disaggregation of asphaltene in oil, and some intertwining super-molecules in asphaltene were dissociated into smaller structures, resulting in exposure of the inner core to the hydrotreating catalyst. Therefore, the nucleus was hydrotreated and its average molecular weight decreased. This corroborated our previous conclusion [21].

3.2. XRD Studies of Asphaltenes. The XRD patterns of these asphaltenes recorded at room temperature were deconvoluted (see Figures 2 and 3). It is reported that the XRD pattern 


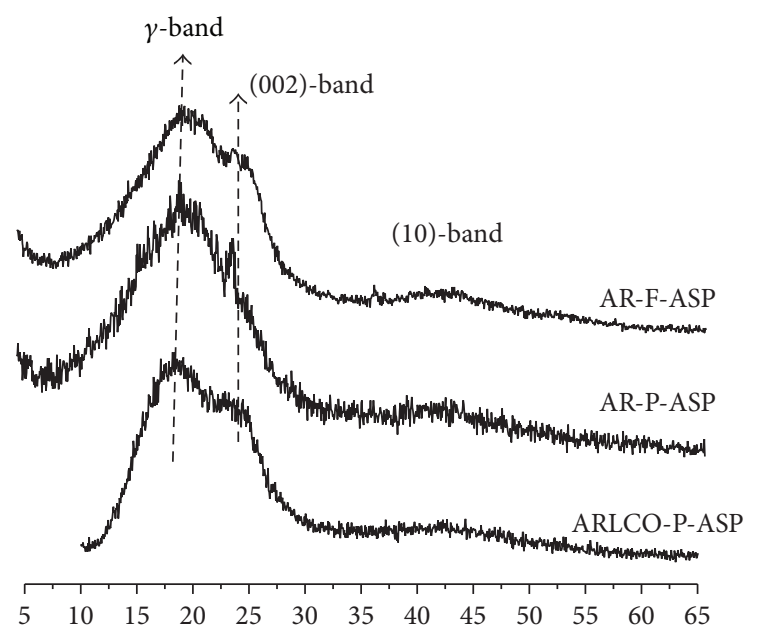

FIGURE 2: XRD patterns of different asphaltene samples.

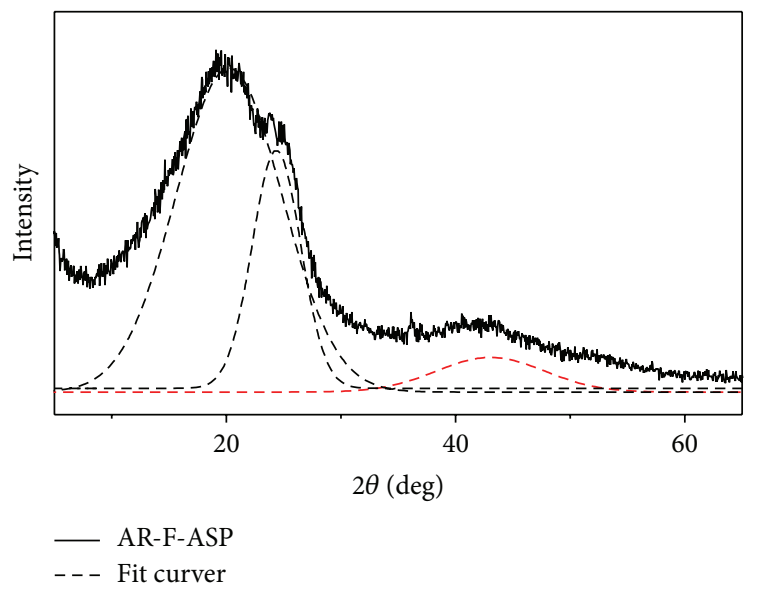

FIGURE 3: Deconvoluted XRD pattern of asphaltene of atmospheric residue (AR-F-ASP as an example).

of asphaltenes has four characteristic peaks at $d \approx 4.8 \AA$ (gamma band), $3.5 \AA$ ((002) band), $2.1 \AA$ ((10) band), and $1.2 \AA$ ((11) band) $[23,31]$. The peak position of the gamma band provides information about the distance between the two aliphatic chains or saturated rings $\left(d_{r}\right)$. Similarly, the distance between two aromatic sheets, $d_{m}$, was obtained from the peak position of the (002) band [4]. The size of the aromatic sheet, $L_{a}$, was obtained from either the (10) or (11) band. Cluster diameter $\left(L_{c}\right)$, the average number of aromatic sheets $\left(M_{e}\right)$, the average number of aromatic rings in each aromatic sheet $\left(R_{a}\right)$, and the number of carbons per aromatic structural unit $\left(\mathrm{C}_{\mathrm{Au}}\right)$ can be calculated from the measured data according to the equations listed in Table 2.

Comparing the structural parameters of the three asphaltenes in Table 2, it can be seen that when the asphaltene was hydrotreated, the distance between the two aliphatic chains was increased to $4.53 \AA$ and $4.63 \AA$ from $4.39 \AA$ for nonhydrotreated asphaltene, whereas the distance between the two aromatic sheets $\left(d_{m}\right)$ decreased slightly by approximately 0.11 to $0.25 \AA$. This was due to the removal of aliphatic

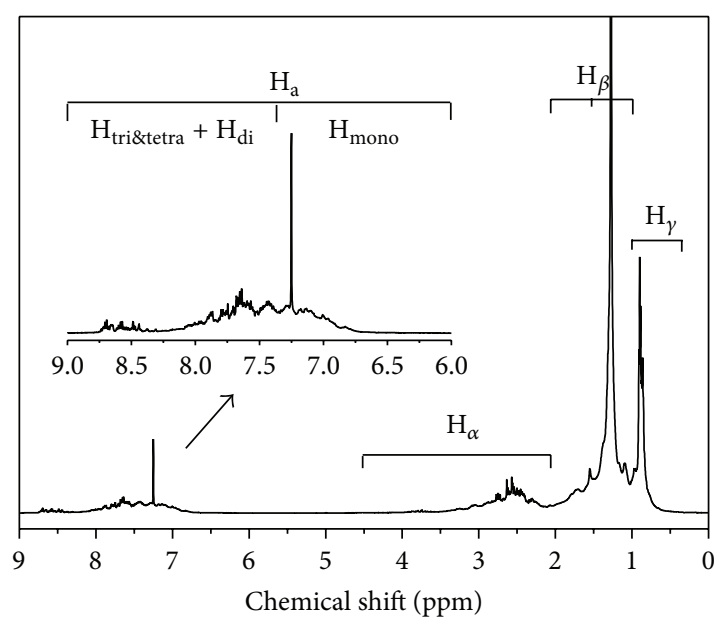

FIgURE $4:{ }^{1} \mathrm{H}-\mathrm{NMR}$ spectra of asphaltene.

chains or hydrogenation of saturated rings during severe hydroprocessing: this resulted in a shortening of branch chains and the aggregation of aromatic units. After residue hydrotreatment, the significant decrease of $M_{e}$ (from its initial value of 6.90 to 5.48 and 4.90 ) demonstrated that a part of the loose, reactive, aromatic compositions around aromatic cores were hydrogenated, corresponding to a significant decrease in the size of each aromatic cluster $\left(L_{c}\right.$ or $\left.L_{a}\right)$.

Comparing the structural parameters of AR-P-ASP with those of ARLCO-P-ASP in Table 2, the basic parameters $L_{c}$ and $L_{a}$ of ARLCO-P-ASP decreased, resulting in decreases in $M_{e}, R_{a}$, and $\mathrm{C}_{\mathrm{Au}}$, suggesting that ARLCO-P-ASP was smaller and had fewer carbon aromatic sheets than ARP-ASP. Accordingly, the slightly larger $d_{m}$ and $d_{r}$ values demonstrated a larger distance between aromatic sheets and aliphatic chains in ARLCO-P-ASP. From these parameters, it was deduced that the addition of high-aromaticity LCO increased the solubility of aromatic compounds in oil and improved the liberation of asphaltene aggregates, leading to a relative loose structure of the asphaltene in blends of AR and LCO, which was favourable to hydrogenation during HDT. Consequently, the hydrotreated asphaltene ARLCO-P-ASP showed the aforementioned advantages.

3.3. NMR Studies of Asphaltenes. Table 3 defines carbon and hydrogen types obtained by ${ }^{13} \mathrm{C}$ and ${ }^{1} \mathrm{H}$ NMR spectroscopy. The ${ }^{13} \mathrm{C}$ and ${ }^{1} \mathrm{H}$ NMR spectra of AR-P-ASP, as examples, are shown in Figures 4 and 5 with assignments of different types of protons giving absorption in characteristic chemical shift regions. The literature summarises a number of rules for obtaining a set of reliable structural parameters from ${ }^{13} \mathrm{C}$ and ${ }^{1} \mathrm{H}$ NMR analyses [14-19]. According to these rules, Table 4 defines the average structural parameters calculated from the ${ }^{13} \mathrm{C}$ and ${ }^{1} \mathrm{H}$ NMR analyses and gives the equations of the resulting structural parameters. The results are shown in Table 5.

The difference between the average structural parameters of AR-F-ASP and AR-P-ASP is apparent in Table 5. The aromaticity factor $\left(f_{a}\right)$ and degree of aromatic condensation 
TABLE 2: Structural data obtained by XRD.

\begin{tabular}{|c|c|c|c|c|c|}
\hline & AR-F-ASP & AR-P-ASP & ARLCO-P-ASP & Equation $^{*}$ & Reference \\
\hline$d_{r}, \AA$ & 4.39 & 4.53 & 4.63 & $d_{r}=\lambda /\left(2 \sin \theta_{\gamma}\right)$ & {$[23]$} \\
\hline$d_{m}, \AA$ & 3.81 & 3.56 & 3.70 & $d_{m}=\lambda /\left(2 \sin \theta_{002}\right)$ & {$[23]$} \\
\hline$L_{c}, \AA$ & 26.29 & 19.51 & 18.13 & $L_{c}=0.9 \lambda /\left(\omega \cos \theta_{002}\right)=0.45 / B_{1 / 2}$ & {$[23]$} \\
\hline$M_{e}$ & 6.90 & 5.48 & 4.90 & $M_{e}=L_{c} / d_{m}$ & {$[23]$} \\
\hline$L_{a}, \AA$ & 13.04 & 10.43 & 9.23 & $L_{a}=1.84 \lambda /\left(\omega \cos \theta_{10}\right)=0.92 / B_{1 / 2}$ & {$[23]$} \\
\hline$R_{a}$ & 4.70 & 4.36 & 3.46 & $R_{a}=L_{a} / 2.667$ & {$[24]$} \\
\hline$\underline{\mathrm{C}_{\mathrm{Au}}}$ & 22.39 & 20.91 & 17.01 & $\mathrm{C}_{\mathrm{AU}}=\left(L_{a}+1.23\right) / 0.65$ & {$[24]$} \\
\hline
\end{tabular}

${ }^{*}$ Where $\lambda=1.54055 \AA ; \theta_{\gamma}, \theta_{002}$, and $\theta_{10}$ are the diffraction angles of $\gamma, 002$, and 10 bands, respectively; $B_{1 / 2}$ is the width at half maximum of diffraction peak.

TABLE 3: Carbon and hydrogen types obtained by ${ }^{13} \mathrm{C}-\mathrm{NMR}$ and ${ }^{1} \mathrm{H}-\mathrm{NMR}$ spectroscopy.

\begin{tabular}{|c|c|c|c|c|}
\hline Subject & Factor & Chemical shift (ppm) & Detail & Reference \\
\hline \multirow{4}{*}{ Aromatic carbon } & $\mathrm{C}_{\mathrm{Ar}}$ & $100 \sim 170$ & Unsaturated $\mathrm{sp}^{2}, \delta \mathrm{C}_{\mathrm{a}}$ & a \\
\hline & $\mathrm{C}_{\mathrm{Ar}-\mathrm{O}}$ & $140 \sim 170$ & $\begin{array}{l}\text { Oxygenated aromatic carbon atoms to phenolic } \\
\text { hydroxyl, methoxy, and aromatic ether oxygen atoms }\end{array}$ & \multirow{3}{*}[25]{} \\
\hline & $\mathrm{C}_{\mathrm{Ar}-\mathrm{H}}$ & $129-140$ & Aromatic carbon atoms to hydrogen & \\
\hline & $\mathrm{C}_{\mathrm{Ar}-\mathrm{C}}$ & $100 \sim 129$ & $\begin{array}{l}\text { Bridgehead and substituted aromatic carbon atoms } \\
\text { bound to hydroaromatic } \mathrm{CH}_{2} \text { carbon and alkyl side } \\
\text { chains }\end{array}$ & \\
\hline \multirow{4}{*}{ Aliphatic carbon } & $\mathrm{C}_{\mathrm{Ali}}$ & $-10 \sim 70$ & Saturated $\mathrm{sp}^{3}, \delta \mathrm{C}_{\mathrm{s}}$ & a \\
\hline & $\mathrm{C}_{\mathrm{A} 1}$ & $21.9 \sim 60$ & $\mathrm{CH}_{2}$ carbon & \multirow{3}{*}[26]{} \\
\hline & $\mathrm{C}_{\mathrm{A} 2}$ & $17 \sim 21.9$ & $\mathrm{CH}_{3}$ alpha to aromatic ring & \\
\hline & $\mathrm{C}_{\mathrm{A} 3}$ & $8.5 \sim 17$ & Ethyl and further alkyl to aromatic ring carbon content & \\
\hline \multirow{4}{*}{ Aromatic hydrogen } & $\mathrm{H}_{\mathrm{Ar}}$ & $5 \sim 10$ & $\delta \mathrm{CH}_{\mathrm{a}}$ & a \\
\hline & $\mathrm{H}_{\text {tri \& tetra }}$ & $8.3 \sim 8.9$ & Some tri- and tetra-aromatic rings & \multirow{3}{*}[27]{} \\
\hline & $\mathrm{H}_{\mathrm{di}+}$ & $7.2 \sim 8.3$ & Diaromatic and most of tri- and tetra-aromatic rings & \\
\hline & $\mathrm{H}_{\text {mono }}$ & $6.0 \sim 7.2$ & Mono-aromatic ring & \\
\hline \multirow{4}{*}{ Aliphatic hydrogen } & $\mathrm{H}_{\mathrm{Ali}}$ & $-0.5 \sim 5$ & Aliphatic hydrogen & \multirow{4}{*}[28]{} \\
\hline & $\mathrm{H}_{\alpha}$ & $2.0 \sim 4.0$ & $\delta \alpha-\mathrm{CH}_{n}$ & \\
\hline & $\mathrm{H}_{\beta}$ & $1.05 \sim 2.0$ & $\delta \beta-\mathrm{CH}_{n}$ & \\
\hline & $\mathrm{H}_{\gamma}$ & $0.3 \sim 1.0$ & $\delta \gamma-\mathrm{CH}_{3}$ & \\
\hline
\end{tabular}

aSTM D5292-99 (2004) Standard Test Method for Aromatic Carbon Contents of Hydrocarbon Oils by HR-NMR.

$(\gamma)$ of hydrotreated asphaltene AR-P-ASP were much greater than those of AR-F-ASP, whereas the parameters governing aromatic substitution $\left(\sigma\right.$ and $R_{\mathrm{ac}}$ ) and the total number of aromatic rings $\left(R_{\mathrm{at}}\right)$ are much less. According to Sharma et al. [32], fused ring systems have a propensity to stack by van der Waals interaction (and dipolar interactions, etc.), thereby decreasing the solubility of aromatic nuclei in a petroleum colloidal system. Alkane peripheral substituents are favourable to steric interaction thereby increasing such solubility. Larger ring systems require more alkane substituents to maintain a balance between ring stacking propensities as opposed to steric repulsion. During RHT, alkyl substituents around the aromatic core were hydrogenated and ruptured. This balance was partly broken, resulting in condensation of the inner core.
Although the structural parameters of hydrotreated products ARLCO-P-ASP and AR-P-ASP may seem similar, some positive effects of LCO nevertheless remain in evidence. The degree of aromatic substitution $\sigma$ of ARLCO-P-ASP was greater than that of AR-P-ASP whereas the degree of aromatic condensation $\gamma$ was slightly lower. As mentioned above, addition of a high-aromaticity additive (e.g., LCO) can modify the nature of an asphaltene colloid by improving the ease with which resins bound to the asphaltene could be transferred into the oil. Consequently, asphaltene became less compact and was easily dissociated into smaller structures under hydrotreatment conditions: this was beneficial for the hydrotreatment of aromatic cores. Meanwhile, the $\mathrm{H} / \mathrm{C}$ atomic ratios of ARLCO-P-ASP, such as $(\mathrm{H} / \mathrm{C})_{\mathrm{ar}},(\mathrm{H} / \mathrm{C})_{\text {sat }}$, and $(\mathrm{H} / \mathrm{C})_{T}$, were greater than those of AR-P-ASP. These 
TABLE 4: Definition of average structural parameters.

\begin{tabular}{|c|c|c|}
\hline & definition & Equation \\
\hline$(\mathrm{H} / \mathrm{C})_{\mathrm{ar}},(\mathrm{H} / \mathrm{C})_{\mathrm{sat}}$ & $\begin{array}{l}\text { Hydrogen/carbon atomic ratio of aromatics or } \\
\text { saturates }\end{array}$ & \\
\hline$(\mathrm{H} / \mathrm{C})_{T}$ & $\begin{array}{l}\text { Total hydrogen/carbon atomic ratio per } \\
\text { average molecule }\end{array}$ & \\
\hline$f_{a}$ & $\begin{array}{l}\text { Aromaticity factor or fraction of aromatic } \\
\text { carbons }\end{array}$ & $f_{a}=\mathrm{C}_{\mathrm{Ar}} /\left(\mathrm{C}_{\mathrm{Ar}}+\mathrm{C}_{\mathrm{Ali}}\right)=\mathrm{C}_{\mathrm{Ar}} / \mathrm{C}_{T}$ \\
\hline$R_{\mathrm{ac}}$ & $\begin{array}{l}\text { Average number of carbon atoms per alkyl } \\
\text { substituent }\end{array}$ & $R_{\mathrm{ac}}=\left(\mathrm{H}_{\alpha}+\mathrm{H}_{\beta}+\mathrm{H}_{\gamma}\right) / \mathrm{H}_{\alpha}$ \\
\hline$\sigma$ & Degree of aromatic substitution & $\sigma=\left(\left(\mathrm{H}_{\alpha} / 2\right) /\left(\mathrm{H}_{\mathrm{a}}+\mathrm{H}_{\alpha} / 2\right)\right) \mathrm{C}_{T}$ \\
\hline$\gamma$ & Degree of aromatic condensation & $\gamma=\left[\mathrm{C}_{T}-\left(\mathrm{H}_{\mathrm{a}}+\mathrm{H}_{\alpha} / 2+\mathrm{H}_{\beta 1}+\mathrm{H}_{\beta 2} / 2+\mathrm{H}_{\gamma}\right)\right] / \mathrm{C}_{\mathrm{Ar}}$ \\
\hline $\mathrm{C}_{\mathrm{a}}^{*}$ & The absolute of aromatic carbon atoms & $\mathrm{C}_{\mathrm{a}}^{*}=\left[7\left(\mathrm{C}_{\mathrm{Ar}} /\left(\mathrm{H}_{\mathrm{a}}+\mathrm{H}_{\alpha} / 2\right)\right)^{2}-1\right]$ \\
\hline$R_{\mathrm{at}}$ & Total number of aromatic rings per unit sheet & $R_{\mathrm{at}}=\left(\mathrm{C}_{\mathrm{a}}^{*} / f_{a}\right)\left[\mathrm{C}_{T}-\left(\mathrm{H}_{\mathrm{a}}+\mathrm{H}_{\alpha} / 2+\mathrm{H}_{\beta 1}+\mathrm{H}_{\beta 2} / 2+\mathrm{H}_{\gamma}\right)\right] / \mathrm{C}_{T}$ \\
\hline$N$ & $\begin{array}{l}\text { The number of aromatic structural units per } \\
\text { unit sheet of molecules }\end{array}$ & $N=\mathrm{C}_{\mathrm{a}}{ }^{*} / \mathrm{C}_{\mathrm{Au}}{ }^{*}=\mathrm{C}_{\mathrm{a}}^{*}\left(L_{a} \times f_{a}+1.23\right) / 0.615$ \\
\hline
\end{tabular}

${ }^{*}$ Where $\mathrm{H}$ and $\mathrm{C}$ are area of the fitting peaks after normalization. References $[29,30]$.

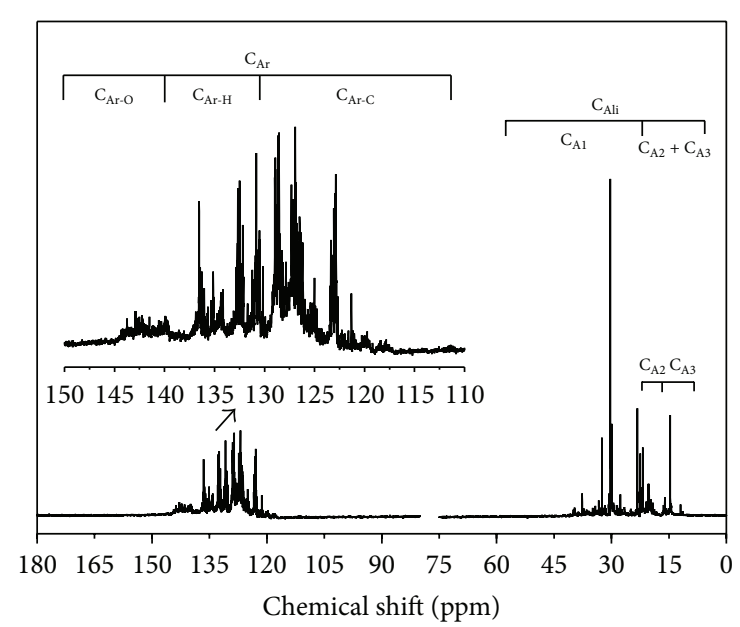

Figure 5: ${ }^{13} \mathrm{C}$-NMR spectra of asphaltene.

observations suggested that the addition of LCO promoted ring opening and the supply of hydrogen when aromatic cores were hydrogenated in oil. This relative, hydrogen-rich, loose structure was beneficial in the further hydrotreatment of asphaltene.

3.4. Average Structural Models of Asphaltenes. The average structural parameters of asphaltenes deduced from NMR and XRD analyses revealed many important differences in the structures of these asphaltenes. Here, we attempted to construct three average structural models for further mapping the changes undergone by the asphaltenes during residue hydrotreatment.
TABLE 5: Average structural parameters of asphaltenes obtained by ${ }^{13} \mathrm{C}-\mathrm{NMR}$ and ${ }^{1} \mathrm{H}-\mathrm{NMR}$.

\begin{tabular}{lccc}
\hline & AR-F-ASP & AR-P-ASP & ARLCO-P-ASP \\
\hline$f_{a}$ & 0.47 & 0.58 & 0.52 \\
$\sigma$ & 0.62 & 0.46 & 0.50 \\
$\gamma$ & 0.52 & 0.61 & 0.57 \\
$R_{\mathrm{at}}$ & 17.15 & 14.60 & 13.30 \\
$R_{\mathrm{ac}}$ & 9.00 & 4.36 & 5.21 \\
$(\mathrm{H} / \mathrm{C})_{\mathrm{ar}}$ & 0.21 & 0.16 & 0.18 \\
$(\mathrm{H} / \mathrm{C})_{\mathrm{sat}}$ & 1.66 & 1.78 & 1.81 \\
$(\mathrm{H} / \mathrm{C})_{T}$ & 0.98 & 0.89 & 0.93 \\
$N$ & 3.26 & 2.49 & 2.72 \\
\hline
\end{tabular}

The number of aromatic structural units $(N)$ of asphaltenes is between 2.49 and 3.26 (Table 5), which indicated that three aromatic sheets were joined together through several naphthenic rings. The total number of aromatic rings $\left(R_{\mathrm{at}}\right)$ ranged from 13.30 to 17.15 , suggesting about five aromatic rings per aromatic sheet. Hydrotreated asphaltenes have shorter straight paraffinic chains $\left(R_{\mathrm{ac}}=5.21,4.36\right)$ than nonhydroprocessed asphaltene $\left(R_{\mathrm{ac}}=9.00\right)$. As seen in Table 1, some heteroatomic $\mathrm{S}, \mathrm{O}$, and $\mathrm{N}$ were inserted in each structural unit. Based on these average structural parameters derived from the combined NMR, XRD, element analysis, and molecular weight data, it was possible to propose three hypothetical average model structures for the asphaltenes as shown in Figure 6. These structural models showed the changes undergone by the asphaltenes during HDT and the effects of additive LCO thereon. 


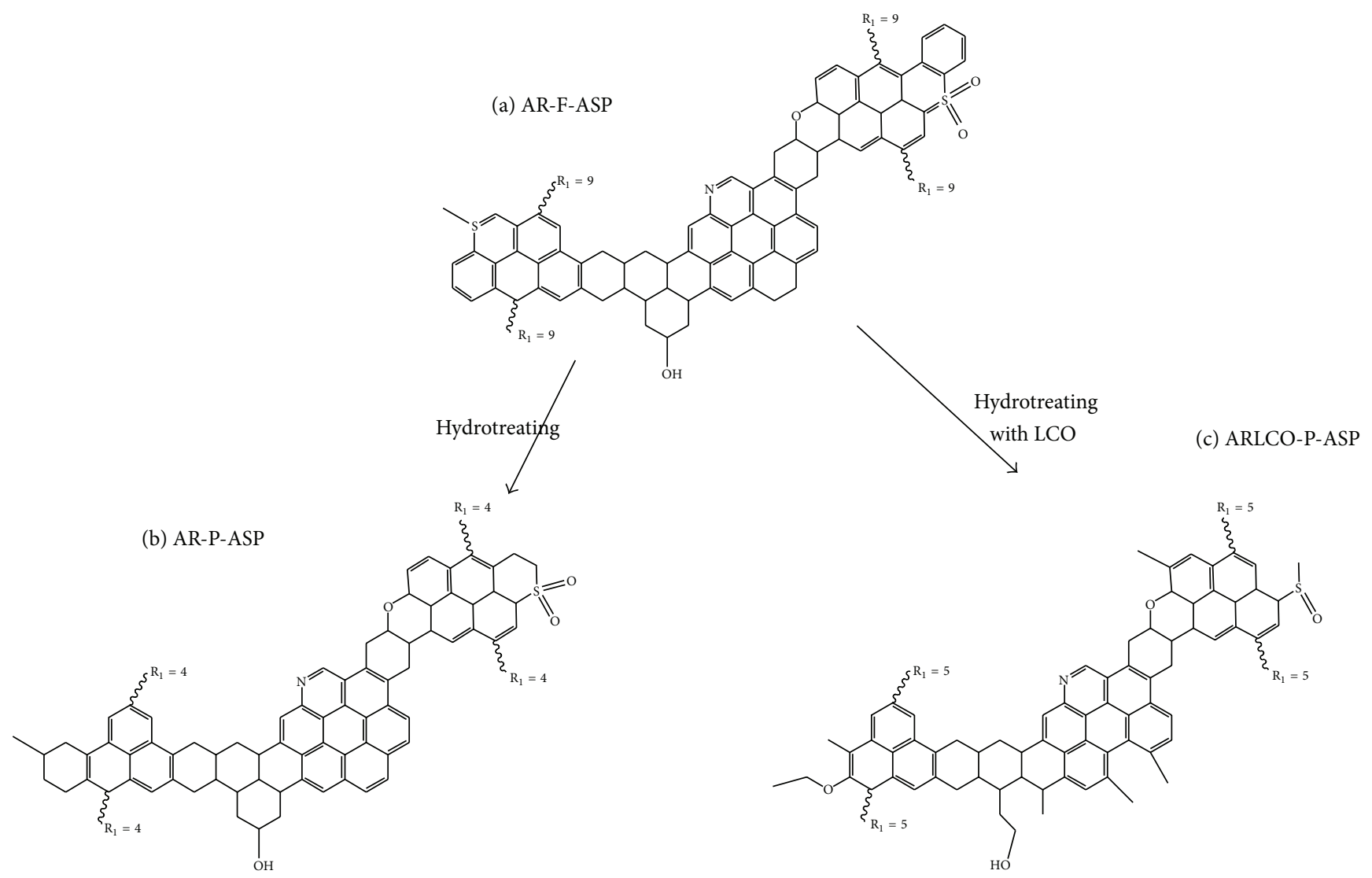

FIGURE 6: Model structures of asphaltenes' aromatic rings.

\section{Conclusions}

Asphaltene has perplexed researchers since petroleum was first used industrially. It has already become a key for developing the technology of residue hydrotreatment when seeking an understanding of the properties of, and changes in, asphaltene. Here, we attempted to provide novel insights into the structural evolution of asphaltenes during residue hydrotreatment from the microstructural, and average parameter, perspectives.

There was a dissolution equilibrium between the nucleus of asphaltene and its surrounding solvate shell. During residue hydrotreatment, this equilibrium played a key role and was easily changed by reaction conditions and the presence of certain additives. From the above discussion, the average structural parameters of asphaltenes demonstrated that the aromatic cores of hydrotreated asphaltenes had become more compact and smaller; meanwhile the alkyl branches both decreased in number and became shorter. However, aromatic LCO, when added into the feedstock, partly improved this situation. The distance between aromatic sheets and aliphatic chains, the degree of aromatic substitution, and the total $\mathrm{H} / \mathrm{C}$ atomic ratio per average molecule of ARLCO$\mathrm{P}$-ASP increased as the degree of aromatic condensation and size of aromatic sheets decreased (relatively), which was beneficial for the further hydrotreatment of asphaltene.
The parameters obtained allowed construction of hypothetical average molecular models for asphaltenes. These model structures represented the changes undergone by asphaltenes during RHT as well as the effect of LCO addition. However, it must be emphasized that values obtained are only average values. It is unlikely that any one molecule in the asphaltenes will actually have the hypothetical structure. But knowledge of the kinds of molecules found in these complex asphaltenes will aid in understanding the physical and chemical behaviors during HDT.

\section{Conflict of Interests}

The authors declare that there is no conflict of interests regarding the publication of this paper.

\section{Acknowledgments}

This work was financially supported by the Research Foundation of Educational Bureau of Fujian Province (JA12008) and the Project of Quanzhou Science and Technology Plan (2013Z23).

\section{References}

[1] E. Y. Sheu, "Petroleum asphaltene-properties, characterization, and issues," Energy and Fuels, vol. 16, no. 1, pp. 74-82, 2002. 
[2] O. C. Mullins, D. J. Seifert, J. Y. Zuo, and M. Zeybek, "Clusters of asphaltene nanoaggregates observed in oilfield reservoirs," Energy \& Fuels, vol. 27, no. 4, pp. 1752-1761, 2013.

[3] O. C. Mullins, "The asphaltenes," Annual Review of Analytical Chemistry, vol. 4, pp. 393-418, 2011.

[4] Z. Hosseini-Dastgerdi, S. A. R. Tabatabaei-Nejad, E. Khodapanah, and E. Sahraei, "A comprehensive study on mechanism of formation and techniques to diagnose asphaltene structure; molecular and aggregates: a review," Asia-Pacific Journal of Chemical Engineering, vol. 10, no. 1, pp. 1-14, 2015.

[5] Z. Hosseini-Dastgerdi, S. A. R. Tabatabaei-Nejad, E. Sahraei et al., "Morphology and size distribution characterization of precipitated asphaltene from live oil during pressure depletion," Journal of Dispersion Science and Technology, vol. 36, no. 3, pp. 363-368, 2015.

[6] M. Morimoto, T. Sato, S. Araki et al., "Mapping the degree of asphaltene aggregation, determined using Rayleigh scattering measurements and Hansen solubility parameters," Energy \& Fuels, 2014.

[7] S. Wang, C. Yang, C. Xu, S. Zhao, and Q. Shi, "Separation and characterization of petroleum asphaltene fractions by ESI FTICR MS and UV-vis spectrometer," Science China Chemistry, vol. 56, no. 7, pp. 856-862, 2013.

[8] J. C. Franco, G. Gonçalves, M. S. Souza et al., "Towards in situ fluorescence spectroscopy and microscopy investigations of asphaltene precipitation kinetics," Optics Express, vol. 21, no. 25, pp. 30874-30885, 2013.

[9] J. Eyssautier, P. Levitz, D. Espinat et al., "Insight into asphaltene nanoaggregate structure inferred by small angle neutron and $\mathrm{X}$ ray scattering," The Journal of Physical Chemistry B, vol. 115, no. 21, pp. 6827-6837, 2011.

[10] L. Filippelli, L. Gentile, C. O. Rossi, G. A. Ranieri, and F. E. Antunes, "Structural change of bitumen in the recycling process by using rheology and NMR," Industrial and Engineering Chemistry Research, vol. 51, no. 50, pp. 16346-16353, 2012.

[11] T. Fergoug and Y. Bouhadda, "Determination of Hassi Messaoud asphaltene aromatic structure from ${ }^{1} \mathrm{H} \&{ }^{13} \mathrm{C}$ NMR analysis," Fuel, vol. 115, pp. 521-526, 2014.

[12] E. C. da Silva Oliveira, Á. C. Neto, V. L. Júnior, E. V. R. de Castro, and S. M. C. de Menezes, "Study of Brazilian asphaltene aggregation by Nuclear Magnetic Resonance spectroscopy," Fuel, vol. 117, pp. 146-151, 2014.

[13] Q. Xu, Z. Zhang, S. Zhang, F. Wang, and Y. Yan, "Molecular structure models of asphaltene in crude and upgraded bio-oil," Chemical Engineering \& Technology, vol. 37, no. 7, pp. 1198-1204, 2014.

[14] A. Hauser, F. AlHumaidan, H. Al-Rabiah, and M. A. Halabi, "Study on thermal cracking of Kuwaiti heavy oil (vacuum residue) and its SARA fractions by NMR spectroscopy," Energy \& Fuels, vol. 28, no. 7, pp. 4321-4332, 2014.

[15] S. I. Andersen, J. O. Jensen, and J. G. Speight, "X-ray diffraction of subfractions of petroleum asphaltenes," Energy and Fuels, vol. 19, no. 6, pp. 2371-2377, 2005.

[16] M. N. Siddiqui, M. F. Ali, and J. Shirokoff, "Use of X-ray diffraction in assessing the aging pattern of asphalt fractions," Fuel, vol. 81, no. 1, pp. 51-58, 2002.

[17] D. Liu, Z. Li, Y. Fu et al., "Investigation on asphaltene structures during venezuela heavy oil hydrocracking under various hydrogen pressures," Energy and Fuels, vol. 27, no. 7, pp. 3692-3698, 2013.
[18] M. N. Siddiqui, "Catalytic pyrolysis of Arab heavy residue and effects on the chemistry of asphaltene," Journal of Analytical and Applied Pyrolysis, vol. 89, no. 2, pp. 278-285, 2010.

[19] D. Lesueur, "The colloidal structure of bitumen: consequences on the rheology and on the mechanisms of bitumen modification," Advances in Colloid and Interface Science, vol. 145, no. 1-2, pp. 42-82, 2009.

[20] F. J. Martín-Martínez, E. H. Fini, and M. J. Buehler, "Molecular asphaltene models based on Clar sextet theory," RSC Advances, vol. 5, no. 1, pp. 753-759, 2015.

[21] Y. Liu and Y. Zou, "Effects of aromatic cycle oils on performance of residue hydrotreating," Korean Journal of Chemical Engineering, vol. 30, no. 11, pp. 1985-1989, 2013.

[22] Y.-J. Liu, "Microstructure characterization of asphaltenes from atmospheric residue before and after hydroprocessing," Journal of Fuel Chemistry and Technology, vol. 40, no. 9, pp. 1086-1091, 2012.

[23] T. F. Yen, J. G. Erdman, and S. S. Pollack, "Investigation of the structure of petroleum aphaltenes by X-ray diffraction," Analytical Chemistry, vol. 33, no. 11, pp. 1587-1594, 1961.

[24] J. Christopher, A. S. Sarpal, G. S. Kapur et al., "Chemical structure of bitumen-derived asphaltenes by nuclear magnetic resonance spectroscopy and X-ray diffractometry," Fuel, vol. 75, no. 8, pp. 999-1008, 1996.

[25] T. Yoshida and Y. Maekawa, "Characterization of coal structure by CP/MAS carbon-13 NMR spectrometry," Fuel Processing Technology, vol. 15, pp. 385-395, 1987.

[26] A. Sakanishi, Y. Korai, I. Mochida et al., "Comparative study of isotropic and mesophase pitches derived from $\mathrm{C}_{9}$ alkylbenzenes," Carbon, vol. 30, no. 3, pp. 459-466, 1992.

[27] B. Diehl, H. Ulrike, W. Iwona et al., "Principles in NMR spectroscopy," in NMR Spectroscopy in Pharmaceutical Analysis, pp. 1-41, Elsevier, Amsterdam, The Netherlands, 2008.

[28] S. W. Lee and B. Glavincevski, "NMR method for determination of aromatics in middle distillate oils," Fuel Processing Technology, vol. 60, no. 1, pp. 81-86, 1999.

[29] S. Gillet, P. Rubini, J.-J. Delpuech, J.-C. Escalier, and P. Valentin, "Quantitative carbon-13 and proton nuclear magnetic resonance spectroscopy of crude oil and petroleum products. I. Some rules for obtaining a set of reliable structural parameters," Fuel, vol. 60, no. 3, pp. 221-225, 1981.

[30] S. Gillet, P. Rubini, J.-J. Delpuech, J.-C. Escalier, and P. Valentin, "Quantitative carbon-13 and proton nuclear magnetic resonance spectroscopy of crude oil and petroleum products. 2 . Average structure parameters of representative samples," Fuel, vol. 60, no. 3, pp. 226-230, 1981.

[31] O. P. Strausz, T. W. Mojelsky, and E. M. Lown, “The molecular structure of asphaltene: an unfolding story," Fuel, vol. 71, no. 12, pp. 1355-1363, 1992.

[32] A. Sharma, H. Groenzin, A. Tomita, and O. C. Mullins, "Probing order in asphaltenes and aromatic ring systems by HRTEM," Energy and Fuels, vol. 16, no. 2, pp. 490-496, 2002. 

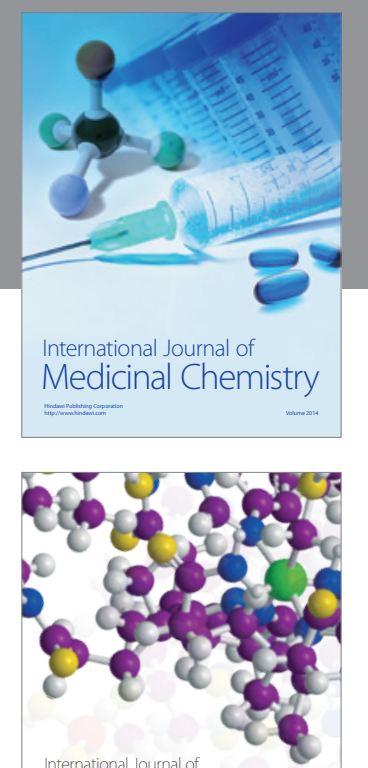

\section{Carbohydrate} Chemistry

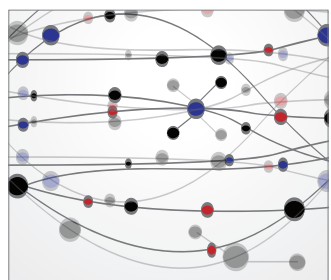

The Scientific World Journal
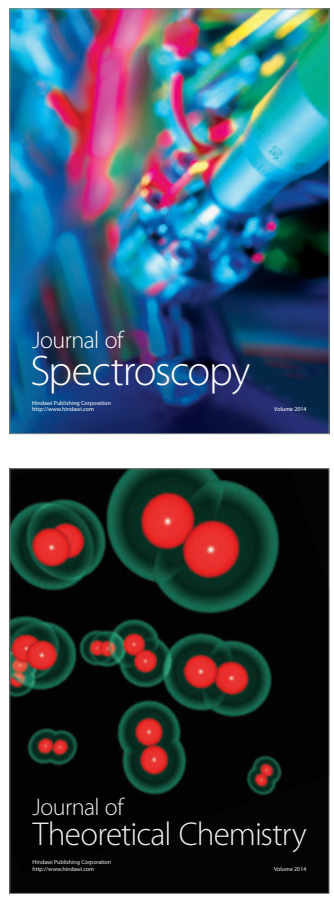
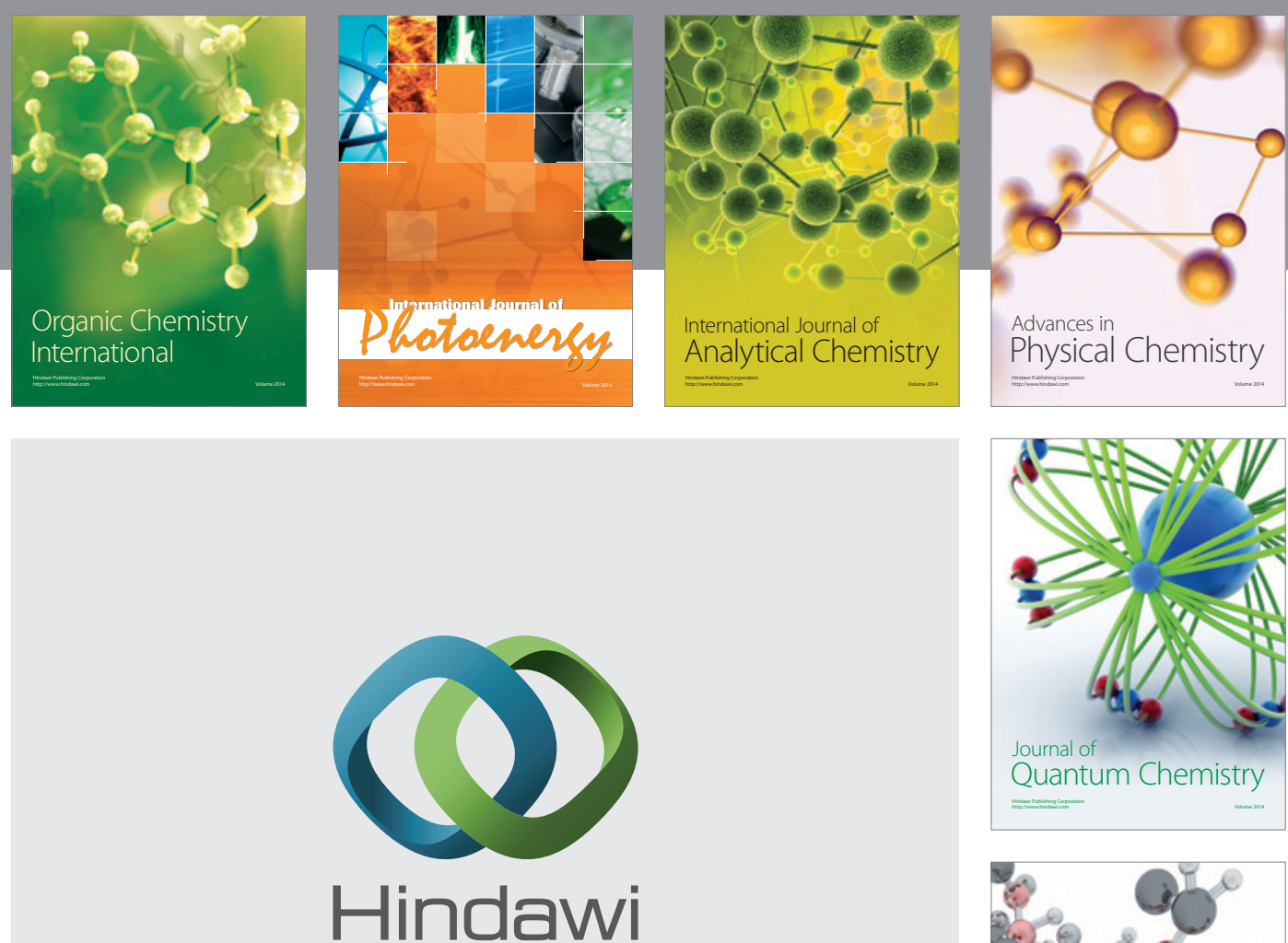

Submit your manuscripts at

http://www.hindawi.com

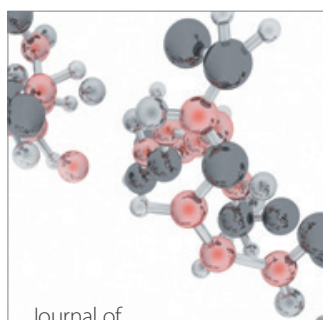

Analytical Methods

in Chemistry

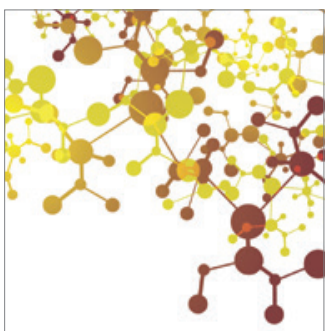

Journal of

Applied Chemistry

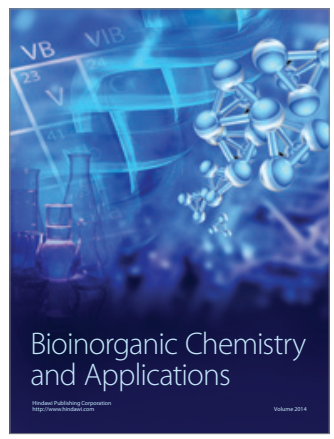

Inorganic Chemistry
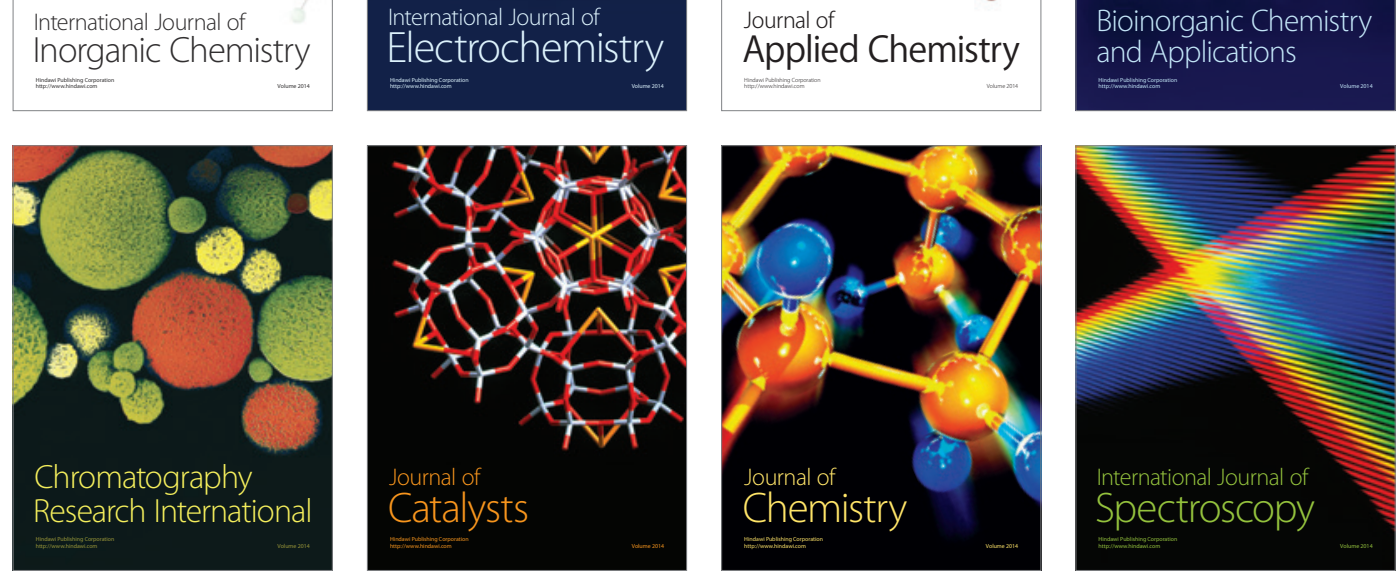